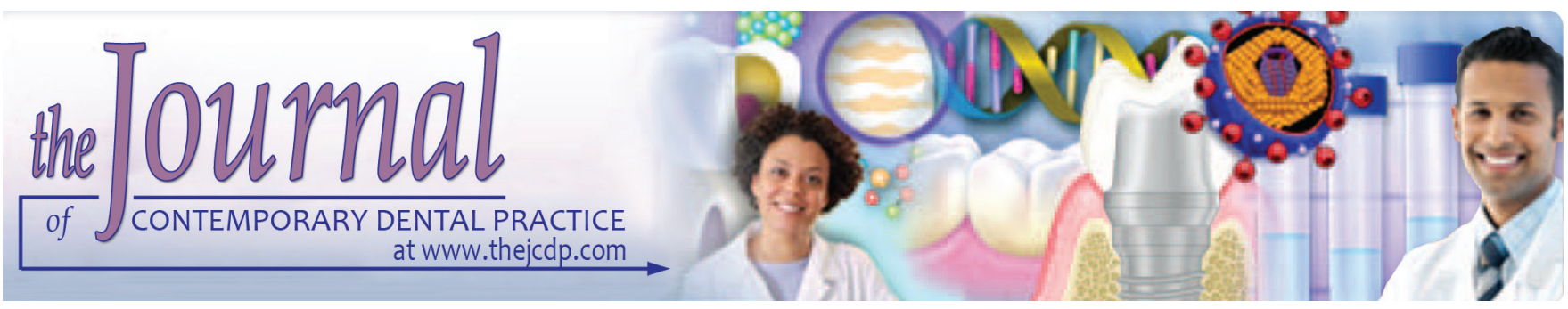

\title{
Comparison of Cuspal Deflection and Microleakage of Premolar Teeth restored with Three Restorative Materials
}

\author{
${ }^{1}$ Ebrahim Yarmohamadi, ${ }^{2}$ Pegah R Jahromi, ${ }^{3}$ Mahdi Akbarzadeh
}

\begin{abstract}
Aim: This study aimed to assess cuspal deflection and microleakage of mesio-occluso-distal (MOD) cavities in premolar teeth restored with three different tooth-colored restorative materials to determine the effect of polymerization shrinkage stress over time.
\end{abstract}

Materials and methods: The MOD cavities ( $4 \mathrm{~mm}$ depth) were prepared in 30 sound human maxillary premolars. The teeth were randomly divided into three groups $(n=10)$. The teeth were then restored with Filtek P60 (group I), X-tra fil (group II), and Admira Fusion $\mathrm{x}$-tra (group III). Cuspal deflection was assessed after 5 minutes, 24 hours, 48 hours, and 7 days by measuring the intercuspal distance. After restoring the teeth, they were subjected to 1,000 thermal cycles and were then immersed in $2 \%$ methylene blue for 24 hours. After vertical section of teeth, they were observed under a stereomicroscope to assess microleakage. Data were analyzed using one-way analysis of variance (ANOVA) and Tukey's honest significant difference (HSD) post hoc test. Friedman test was used to compare different time points in each group and nonparametric Mann-Whitney test was applied to assess microleakage $(\alpha<0.05)$.

Results: The mean cuspal deflection was significantly different in the three groups $(p<0.001)$. The highest deflection was noted in Filtek P60 $(14.8 \pm 1.9)$ and the lowest was noted in Admira Fusion $x$-tra $(7.4 \pm 1.4 \mu \mathrm{m})$. Cuspal deflection significantly decreased after 7 days, but did not return to the baseline value. Admira Fusion $x$-tra showed significantly less deflection after 7 days $(p<0.001)$, but the other two groups were the same $(p=0.3)$. Microleakage was not significantly different among the three groups $(p>0.05)$.

\footnotetext{
1,2Department of Restorative Dentistry, Dental School, Hamadan University of Medical Sciences, Hamadan, Islamic Republic of Iran

${ }^{3}$ Department of Cellular and Molecular Research Center Research Institute for Endocrine Sciences, Shahid Beheshti University of Medical Sciences, Tehran, Islamic Republic of Iran

Correspondence Author: Pegah R Jahromi, Department of Restorative Dentistry, Dental School, Hamadan University of Medical Sciences, Hamadan, Islamic Republic of Iran, Phone: +989173873564, e-mail: pegah.ranjbaran@yahoo.com
}

Conclusion: The lowest cuspal deflection was noted in Admira Fusion $\mathrm{x}$-tra, although marginal microleakage was not significantly different among the groups.

Clinical significance: As the lowest cusp deflection was noted in Admira Fusion $\mathrm{x}$-tra, this restorative material can be suitable for esthetic restoration of extensive posterior cavities.

Keywords: Bulk fill composite, Cuspal deflection, Microleakage, Ormocer

How to cite this article: Yarmohamadi E, Jahromi PR, Akbarzadeh M. Comparison of Cuspal Deflection and Microleakage of Premolar Teeth restored with Three Restorative Materials. J Contemp Dent Pract 2018;19(6):684-689.

Source of support: This study was funded by Vice Chancellor of Research of Hamadan University of Medical Sciences (9509235537).

\section{Conflict of interest: None}

\section{INTRODUCTION}

In recent years, many advances have been made in toothcolored adhesive restorative materials. ${ }^{1}$ Demand for tooth-colored restorations, especially for the posterior teeth, has greatly increased. ${ }^{2}$ Recent evidence supports the use of composite resins in the occlusal and occlusoproximal cavities of posterior teeth. ${ }^{3}$ However, polymerization shrinkage and the resultant stress are still a limitation of composite restorations. ${ }^{4}$ Polymerization shrinkage causes volumetric shrinkage and stress in the restoration and its subsequent debonding, ${ }^{5}$ leading to bacterial microleakage. Microleakage is defined as undetectable passage of bacteria, ions, and liquid through the tooth-restoration interface. ${ }^{6}$ On the contrary, if the bond is strong and remains intact, stress is applied to tooth structure and would cause cuspal deflection or even tooth fracture. ${ }^{7,8}$

Several methods are available to decrease polymerization shrinkage. Incremental application of composite resin is among these methods. ${ }^{9}$ Another method is to change the formulation of composite resin, i.e., increasing the 
percentage of fillers or changing the structure or chemical formulation of monomer. ${ }^{8}$

Methacrylate composites have acceptable performance. ${ }^{5}$ However, due to the presence of triethylene glycol dimethacrylate (TEGDMA) comonomer in their composition, they have higher polymerization rate and increased cuspal deflection, which results in postoperative pain, bacterial microleakage, debonding of composite, marginal discoloration, pulp inflammation, and secondary caries. ${ }^{2,10}$

A new type of composite resin, known as lowshrinkage composite, was recently introduced to the market, which allows bulk application of composite in the cavity. ${ }^{11}$ Its use is easier than conventional composites since they require incremental application. ${ }^{12}$ Due to higher translucency of bulk fill composites, ${ }^{11}$ allowing deeper penetration of light, ${ }^{13}$ these composites can be applied in increments as thick as $4 \mathrm{~mm}$ with minimal shrinkage. ${ }^{14,15}$ Recently, organically modified ceramics (ormocers) were introduced to overcome the problems of composite resins, ${ }^{16}$ since they have lower polymerization shrinkage and stress. ${ }^{2}$ Admira Fusion x-tra is a new ormocer, which is claimed to have lower polymerization shrinkage than other composites (about 1.25\%). ${ }^{15}$ However, conventional composites have a volumetric shrinkage of about 2 to $6 \% .{ }^{17}$ Measurement of microleakage, debonding of composite, postoperative hypersensitivity, recurrent caries, and cuspal deflection rate of restored tooth are among the methods to assess the effects of polymerization shrinkage over time. ${ }^{2,10,18}$ This study aimed to assess the cuspal flection and microleakage following bulk application of two posterior restorative materials, namely Admira Fusion x-tra and X-tra fil composites compared with conventional P60 composite in large MOD cavities after 5 minutes, 24 hours, 48 hours, and 7 days. The null hypothesis was that there would be no significant difference in cuspal deflection of teeth restored with different restorative materials at different time points. Also, the three materials would not be significantly different in terms of microleakage.

\section{MATERIALS AND METHODS}

This in vitro experimental study was performed on 30 sound human maxillary premolars extracted for orthodontic reasons. The teeth were visually inspected to ensure absence of caries, defects, and cracks. Debris and soft tissue residues were removed by a hand scaler. The teeth were then immersed in $10 \%$ formalin and transferred to distilled water at room temperature $(23 \pm$ $\left.1^{\circ} \mathrm{C}\right) 1$ week prior to the experiment. To standardize the buccopalatal width of teeth in each group, first, the buccopalatal width of each tooth was measured at the height of contour using a digital micrometer gauge (Mitutoyo 230-293, resolution $1 \mu \mathrm{m}$, Kawasaki, Japan). The teeth were selected such that the mean standard deviation of buccopalatal width between the groups was less than $5 \%$. Using block randomization method, the teeth were divided into three groups $(n=10)$. Each tooth was mounted in auto-polymerizing acrylic resin (Acropars, Tehran, Iran) in a plastic box with $2 \mathrm{~cm}$ diameter and $2 \mathrm{~cm}$ height to $2 \mathrm{~mm}$ below the cementoenamel junction. To create a reference point for measurement of intercuspal distance, the tip of buccal and palatal cusps of each tooth with approximately $2 \mathrm{~mm}$ diameter was etched with 37\% phosphoric acid (3M ESPE, St. Paul, Minnesota, USA) for 30 seconds. It was then rinsed for 10 seconds and dried with air spray. Single Bond 2 (3M ESPE, St. Paul, Minnesota, USA) was then applied on etched surfaces using a microbrush according to the manufacturer's instructions, light cured with a light-emitting diode (LED) light curing unit (Kerr, Orange, California, USA) with a light intensity of $1,200 \mathrm{~mW} / \mathrm{cm}^{2}$ and cured for 10 seconds. Flowable composite (Filtek Flow; 3M ESPE, St. Paul, Minnesota, USA) in the form of a small ball with $1 \mathrm{~mm}$ diameter was placed on the palatal slope of the palatal cusp and buccal slope of the buccal cusp close to the cusp tip and cured for 20 seconds. After 1 week of immersion in distilled water at room temperature, the distance between the reference balls on each tooth was measured using a digital micrometer and recorded as the baseline intercuspal distance. For each mounted sample, two reference guides were fabricated by auto-polymerizing acrylic resin to increase the accuracy and reproducibility of measurements. These two reference guides enabled fixed position of micrometer for measurement of cuspal deflection. Using a 010 fissure diamond bur (Tizkavan, Tehran, Iran) and high-speed hand-piece under water coolant, large standard MOD cavities were prepared. Mesial and distal boxes with $4 \mathrm{~mm}$ depth and a width equal to $2 / 3$ of the buccopalatal width of each tooth were prepared. Occlusal extension of the cavity was done with an isthmus width $1 / 2$ of the buccopalatal width of each tooth and $4 \mathrm{~mm}$ depth from the cavity margin. The cavosurface margins were $90^{\circ}$ and all internal line angles were rounded. The facial and lingual walls of the cavity were parallel. After preparing five cavities, a new bur was used.

A transparent matrix band (Automatrix, Bioggio, Switzerland) was used for restoration of each tooth and it was removed after completion of restoration. The cervical margin of the matrix band in proximal boxes was held in place with finger pressure during restoration. All teeth were restored as recommended by the manufacturers.

In group I, enamel and dentin were etched with 37\% phosphoric acid (3M ESPE, St. Paul, Minnesota, USA) for 15 seconds and were then rinsed with air and water spray 
for 10 seconds. According to the wet bonding protocol, excess water was removed by an absorbent paper and two layers of Single Bond 2 bonding agent were gently applied by a microbrush for 15 seconds and thinned by 5 seconds of gentle air spray in order for the solvent to evaporate. Curing was then performed for 10 seconds. Filtek P60 composite (A3 shade, 3M ESPE) was applied into the cavity in two $2 \mathrm{~mm}$ thick increments according to the manufacturer's instructions. The occlusal surface was formed anatomically using a burnisher. Each layer was cured for 20 seconds.

The same steps were followed in groups II and III with the difference that restorative materials were applied as bulk in the cavity. In group II, the cavity was filled with X-tra fil (Universal shade; Voco $\mathrm{GmbH}$, Cuxhaven, Germany) and cured for 10 seconds. In group III, the cavity was filled with Admira Fusion x-tra (Universal shade; Voco GmbH, Cuxhaven, Germany) and cured for 20 seconds according to the manufacturer's instructions. During the study period, the teeth were stored in distilled water at room temperature $\left(23 \pm 1^{\circ} \mathrm{C}\right)$. For assessment of cuspal deflection, the distance between the reference balls was measured by a digital micrometer at 5 minutes, 24 hours, 48 hours, and 7 days after the restoration and recorded. Three values were recorded for each tooth and the mean of these values was calculated and used for statistical analysis. Cuspal deflection at each time point was calculated by subtracting the value from the baseline value.

\section{Assessment of Microleakage}

Restored surfaces were polished with low-speed handpiece and diamond bur under water coolant and then with Sof-Lex discs (3M ESPE) from coarse to fine grit. The teeth were then subjected to 1,000 thermal cycles $\left(5-55^{\circ} \mathrm{C}\right.$ with a dwell time of 30 seconds and transfer time of 30 seconds). After drying the teeth, restored surfaces were sealed with two layers of nail varnish except for $1 \mathrm{~mm}$ width around the margins. The root apices were sealed with sticky wax and the teeth were then immersed in $2 \%$ methylene blue $(\mathrm{pH}=7)$ at room temperature for 24 hours. Each tooth was then mounted in a plastic box measuring $2 \mathrm{~cm}$ in diameter and $2 \mathrm{~cm}$ in height filled with auto-polymerizing acrylic resin (Acropars, Tehran, Iran) such that resin was at the level of $2 \mathrm{~mm}$ below the cementoenamel junction. Using a double-blade diamond disk (Mashhad Nemo, Mashhad, Iran), 100 gm load was applied at a crosshead speed of $125 \mathrm{rpm}$ in mesiodistal direction in sagittal plane for vertical sectioning. The sections were evaluated under a stereomicroscope (Wild M3C, Heerburg, Switzerland) at 40× magnification and the degree of microleakage was recorded: 0 indicated no dye penetration; 1 indicated dye penetration to less than $1 / 3$ rd of the cavity depth; 2 indicated dye penetration to gingival floor less than $2 / 3$ rd of the cavity depth; and 3 indicated dye penetration along the gingival wall toward the pulpal floor. All measurements were made by one operator.

\section{Statistical Analysis}

Data were analyzed using Statistical Package for the Social Sciences version 23 (SPSS Inc., Illinois, USA). One-way ANOVA was applied to compare cuspal deflection among the groups $(\alpha<0.05)$. Tukey's HSD post hoc test was used for pairwise comparisons $(\alpha<0.05)$. Friedman test was applied to compare different time points within each group. Nonparametric Mann-Whitney U test was used to compare microleakage among the groups.

\section{RESULTS}

Table 1 shows the mean and standard deviation of cuspal deflection in the three groups. At 5 minutes after the restoration, the highest cuspal deflection was noted in P60 composite group $(14.8 \pm 1.9 \mu \mathrm{m})$, while the lowest cuspal deflection was noted in Admira Fusion x-tra ormocer group $(7.4 \pm 1.4 \mu \mathrm{m})$. The intercuspal distance in all groups increased at 24 and 48 hours and 1 week, but the values did not return to the baseline value at 1 week in any group (Graph 1). One-way ANOVA showed that the mean cuspal deflection was significantly different in the three groups $(\mathrm{p}<0.001)$. Also, the difference in this regard was significant among different time points within each group $(\mathrm{p}<0.001)$. The interaction effect of time and composite was also significant $(\mathrm{p}=0.001)$.

Table 1: Comparison of the mean and standard deviation (SD, $\mu \mathrm{m})$ of cuspal deflection among the composite groups at different time points

\begin{tabular}{llllll}
\hline Time & 5-min Mean $\pm S D$ & 24-hr Mean $\pm S D$ & 48-hr Mean $\pm S D$ & 1-week Mean $\pm S D$ & $p$-value \\
\hline Group & & & & & \\
P60 & $14.8 \pm 1.9^{\mathrm{A} 1}$ & $10.6 \pm 2^{\mathrm{A} 2}$ & $8.5 \pm 2^{\mathrm{A} 3}$ & $3.9 \pm 1^{\mathrm{A} 4}$ & $<0.001$ \\
X-tra fil & $12.7 \pm 1.4^{\mathrm{B} 1}$ & $8.3 \pm 1.3^{\mathrm{B} 2}$ & $5.9 \pm 1.3^{\mathrm{B} 3}$ & $3.1 \pm 1.3^{\mathrm{A} 4}$ & $<0.001$ \\
Admira Fusion $^{\mathrm{C}}$ & $7.4 \pm 1.4^{\mathrm{C} 1}$ & $5.7 \pm 1^{\mathrm{C} 2}$ & $3.9 \pm 0.8^{\mathrm{C} 3}$ & $1.9 \pm 1^{\mathrm{B} 4}$ & $<0.001$ \\
p-value* $^{*}$ & $<0.001$ & $<0.001$ & $<0.001$ & $<0.001$ & \\
\hline
\end{tabular}

*One-way repeated-measures ANOVA analysis; Mean values exhibiting different letters (within columns) and different superscripted numbers (within rows) are significantly different 
Comparison of Cuspal Deflection and Microleakage in Premolar Teeth

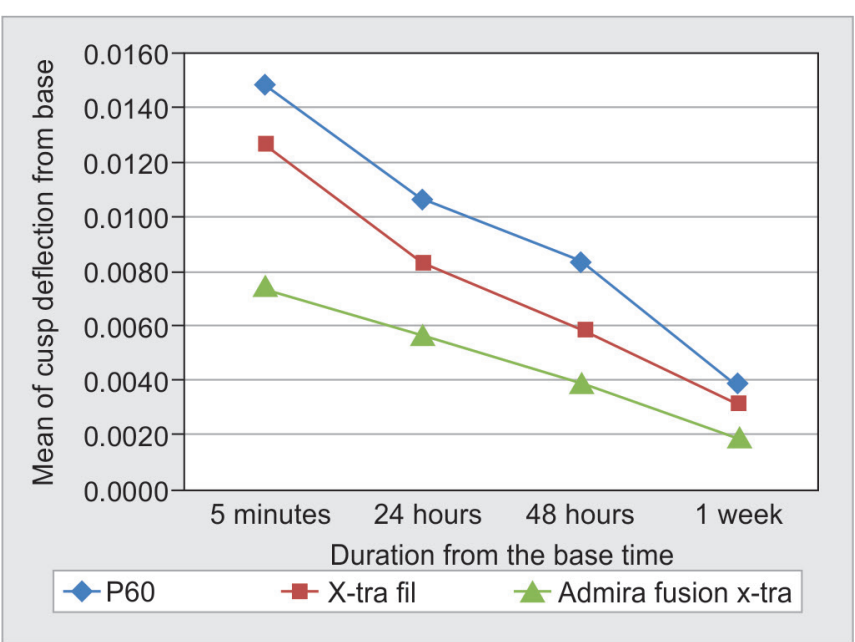

Graph 1: The mean cuspal deflection of the composite groups at different time points

The two bulk fill composites, namely Admira Fusion $x$-tra and X-tra fil showed a significant reduction in cuspal deflection compared with Filtek P60 ( $<<0.001$, Table 2). Also, Admira Fusion showed a significant reduction in cuspal deflection compared with the other two groups $(\mathrm{p}<0.001)$. Tukey's test was applied for pairwise comparison of cuspal deflection of composites at different time points (Table 1). At 5 minutes and 24 and 48 hours, the difference in cuspal deflection among the three groups was significant $(p<0.001)$. At 7 days, the cuspal deflection in Admira Fusion $x$-tra was significantly different from that in P60 and X-tra fil ( $p=0.001$ and $p=0.003$ respectively), but no significant difference was found between P60 and X-tra fil ( $p=0.3)$. Table 2 shows the degree of cervical microleakage in the three groups. Nonparametric Mann-Whitney U test showed no significant difference among the groups in this respect $(\mathrm{p}>0.05)$.

\section{DISCUSSION}

Polymerization shrinkage of composites in the clinical setting causes cracks, cuspal deflection, and tensile deformation, resulting in microleakage and postoperative pain. ${ }^{18}$

Bulk fill composites were introduced to simplify and shorten the process of treatment. These composites can be applied in one increment with up to $4 \mathrm{~mm}$ thickness since these materials are translucent and light can penetrate up to $4 \mathrm{~mm}$ depth. ${ }^{19,20}$ An ideal bulk fill composite must have low volumetric shrinkage and high degree of conversion for application in cavities with high $\mathrm{C}$ factor. ${ }^{21}$ Low-shrinkage composites have high filler content. ${ }^{19}$ These materials go through gel point during polymerization. In this process, superficial layers are hardened but deep layers are still liquid. The flow ability of composites during polymerization can decrease shrinkage stress in these new composites. ${ }^{22}$ Orłowski et $\mathrm{al}^{23}$ compared four
Table 2: Cervical microleakage scores for each posterior filling material

\begin{tabular}{clll}
\hline \multirow{2}{*}{ Samples } & Group I & Group II & Group III \\
\cline { 2 - 4 } & P60 & X-tra fil & Admira Fusion \\
\hline 1 & 2 & 2 & 0 \\
2 & 3 & 2 & 3 \\
3 & 1 & 0 & 0 \\
4 & 3 & 0 & 0 \\
5 & 3 & 3 & 2 \\
6 & 0 & 1 & 1 \\
7 & 1 & 1 & 2 \\
8 & 1 & 2 & 0 \\
9 & 2 & 2 & 1 \\
10 & 2 & 3 & 1 \\
\hline
\end{tabular}

types of bulk fill composites and noticed that they all had acceptable marginal seal and they allowed passage of light into deeper layers due to their translucency. Also, the high content of photoinitiators and stress inhibitors is responsible for maximum seal provided by these composite.

Assessment of enamel cracks and fracture, microleakage, postoperative tooth hypersensitivity, recurrent caries, debonding of composites, and cuspal deflection can help determine the effect of polymerization shrinkage. .,10 $^{2}$ Cuspal deflection depends on several factors, such as size and shape of the cavity, properties of the restorative material, and the bonding system used..$^{8,24}$ Loss of tooth structure directly relates to the cuspal deflection. Also, the greater the loss of tooth structure, the lower the resistance of tooth. ${ }^{25,26}$ In this study, we created a large MOD cavity with $4 \mathrm{~mm}$ depth (corresponding to maximum curing depth of bulk fill composite), standard width of $2 / 3$ of the buccopalatal width in the box and $1 / 2$ of the buccopalatal width at the occlusal isthmus to undermine the tooth structure and cause maximum cuspal deflection to better simulate the clinical setting. ${ }^{8}$

Several methods are used to assess cuspal deflection, such as microscope ${ }^{27}$ strain gauge, ${ }^{28}$ linear variable differential transformer, ${ }^{10}$ and digital micrometer. ${ }^{27,29}$ Digital micrometer was used in this study since it is simpler than other methods and is very sensitive, accurate, and reliable. ${ }^{30}$ Also, the teeth remain moist during measurement, which is an advantage compared with differential transformer method. ${ }^{31}$ For the purpose of standardization, similar to a study by Garapati et al, ${ }^{32}$ size of teeth was chosen such that the difference in buccal width of teeth in groups was $<0.05$.

In this study, maximum cuspal deflection was noted in Filtek P60, which was in line with the results of Karaman and Ozgunaltay, ${ }^{33}$ Cara et $\mathrm{al}^{34}{ }^{34}$ Fleming et al, ${ }^{2}$ and Garapati et al. ${ }^{32}$ The highest cuspal deflection was noted in Filtek P60 group, which may be due to the high content of TEGDMA in P60. The TEGDMA increases the volumetric shrinkage of composite due to increase in 
carbon-carbon bonds and increased degree of conversion of methacrylate bonds. ${ }^{35}$

In this study, X-tra fil bulk fill composite was used to assess its cuspal deflection. The results showed that its cuspal deflection was significantly less than that of Filtek P60, which may be due to higher filler percentage of X-tra fil compared with Filtek P60 (86 vs 78.5 wt\%). Moorthy et $\mathrm{al}^{12}$ assessed cuspal deflection and microleakage of teeth restored with bulk fill flowable composite and showed that cuspal deflection of bulk fill flowable (SDR and X-tra base) was significantly less than that of conventional composite (Grandio SO). Also, El-Damanhoury and Platt $^{36}$ compared bulk fill and conventional composites and reported that X-tra fil bulk fill and Tetric Evoceram had significantly less cuspal deflection than conventional methacrylate composite.

The results of this study showed that cuspal deflection in teeth restored with Admira Fusion x-tra ormocer was significantly less than that of other methacrylate-based restorative materials. Ormocer is a modified organic ceramic composed of organic and inorganic copolymers along with aliphatic and aromatic methacrylate and is claimed to have $1.97 \%$ volumetric shrinkage. ${ }^{2,37}$ Admira Fusion x-tra is a new bulk fill ormocer and the manufacturer claims that it has a volumetric shrinkage less than other materials (about 1.25\%). Also, soluble monomers present in other traditional composites, such as bisphenol A-glycidyl methacrylate, urethane dimethacrylate, hydroxyethyl methacrylate, and TEGDMA are not present in this material, which can be another reason for decreased volumetric shrinkage and significant reduction of cuspal deflection compared with the other two restorative materials. Moreover, the presence of $84 \mathrm{wt} \%$ inorganic nanofillers in its structure can cause better adaptation and decrease volumetric shrinkage of this material. ${ }^{15}$

Fleming et $\mathrm{al}^{2}$ and Garapati et $\mathrm{al}^{32}$ reported that the cuspal deflection of ormocer (Admira) was less than that of Filtek P60, but not significantly. The reason may be different method of application of materials in the cavity. In their studies, composites were applied in triangular increments into MOD cavities.

In our study, similar to that of Elsayd, cuspal deflection was measured 5 minutes after curing of composite since the process of polymerization and change in composite properties continues after cessation of light irradiation. ${ }^{38}$ Also, cuspal deflection was measured 24 and 48 hours later according to previous studies. ${ }^{33,38}$ Since most resins require 7 days to reach a balance, cuspal deflection was also measured after 7 days. ${ }^{39}$

The results of this study showed that the effect of time on cuspal deflection was significant $(p<0.05)$. Over time, cuspal deflection decreased, which was in line with the findings of previous studies. ${ }^{33,40}$ Significant reduction in cuspal deflection after 24 and 48 hours and 7 days of water storage may be due to release of internal stresses of composite by hygroscopic expansion. ${ }^{27,38}$ Some studies have stated that complete or partial recovery to the baseline state may take several weeks. In medium-sized or large restorations, cuspal deflection may never return to the baseline value. ${ }^{40}$ Karamn assessed the cuspal deflection in teeth restored with composite and glass ionomer liner and showed that after 48 hours of water storage, cuspal deflection in all samples approximated the baseline state but never completely returned to the baseline value. ${ }^{33}$

The results of this study showed that 7 days after immersion of samples in water, all samples approximated their baseline state but not completely (Graph 1). Less recovery after 7 days in Admira Fusion x-tra is due to the lower baseline cuspal deflection (at 5 minutes), while cuspal deflection in teeth restored with Admira Fusion $\mathrm{x}$-tra was significantly less compared with the other two groups. In assessment of the cervical margin of the three restorative materials for microleakage, none of the groups showed less microleakage in the cervical margin. The highest dye penetration score (score 3) was noted in all three groups, although in Admira Fusion group the frequency of no dye penetration (score 0) was higher than that in other groups, but this difference was not significant. This finding was in line with that of Fleming et $\mathrm{al}^{2}$ and Garapati et $\mathrm{al}^{32}$ who reported no significant difference in dye penetration between different materials.

\section{CONCLUSION}

Within the limitations of this study, the two bulk fill posterior restorative materials showed less cuspal deflection than the conventional P60 composite, and the lowest cuspal deflection was noted in Admira Fusion $\mathrm{x}$-tra ormocer, although marginal microleakage was not significantly different among the groups.

\section{REFERENCES}

1. Alex TG. Advances in adhesive technology. Curr Opin Cosmet Dent 1995;69-74.

2. Fleming GJ, Hall DP, Shortall AC, Burke FJ. Cuspal movement and microleakage in premolar teeth restored with posterior filling materials of varying reported volumetric shrinkage values. J Dent 2005 Feb;33(2):139-146.

3. Opdam NJM, Bronkhorst EM, Roeters JM, Loomans BAC. A retrospective clinical study on longevity of posterior composite and amalgam restorations. Dent Mater 2007 Jan;23(1):2-8.

4. Labib LM, Nabih SM, Baroudi K. Evaluation of cuspal deflection in premolar teeth restored with low shrinkable resin composite (in vitro study). J Int Soc Prev Community Dent 2015 Nov-Dec;5(6):470-475.

5. Giachetti L, Scaminaci Russo D, Baldini M, Goracci C, Ferrari M. Reparability of aged silorane with methacrylatebased resin composite: micro-shear bond strength and 
scanning electron microscopy evaluation. Oper Dent 2012 Jan-Feb;37(1):28-36.

6. Kidd EA. Microleakage: a review. J Dent 1976 Sep;4(5):199-206.

7. Tantbirojn D, Versluis A, Pintado MR, DeLong R, Douglas WH. Tooth deformation patterns in molars after composite restoration. Dent Mater 2004 Jul;20(6):535-542.

8. Palin WM, Fleming GJ, Nathwani H, Burke FJ, Randall RC. In vitro cuspal deflection and microleakage of maxillary premolars restored with novel low-shrink dental composites. Dent Mater 2005 Apr;21(4):324-335.

9. Kwon Y, Ferracane J, Lee IB. Effect of layering methods, composite type, and flowable liner on the polymerization shrinkage stress of light cured composites. Dent Mater 2012 Jul;28(7):801-809.

10. Abbas G, Fleming GJ, Harrington E, Shortall AC, Burke FJ. Cuspal movement and microleakage in premolar teeth restored with a packable composite cured in bulk or in increments. J Dent 2003 Aug;31(6):437-444.

11. Leprince JG, Palin WM, Vanacker J, Sabbagh J, Devaux J, Leloup G. Physico-mechanical characteristics of commercially available bulk-fill composites. J Dent 2014 Aug;42(8):993-1000.

12. Moorthy A, Hogg CH, Dowling AH, Grufferty BF, Benetti AR, Fleming GJ. Cuspal deflection and microleakage in premolar teeth restored with bulk-fill flowable resin-based composite base materials. J Dent 2012 Jun;40(6):500-505.

13. Fleming GJ, Awan M, Cooper PR, Sloan AJ. The potential of a resin-composite to be cured to a $4 \mathrm{~mm}$ depth. Dent Mater 2008 Apr;24(4):522-529.

14. X-tra fill Instructions for use. VOCO. 2011.

15. Admira fusion X-tra Instructions for use. VOCO. 2015.

16. Cunha LG, Alonso RC, Santos PH, Sinhoreti MA. Comparative study of the surface roughness of ormocer-based and conventional composites. J Appl Oral Sci 2003 Dec;11(4):348-353.

17. Labella R, Lambrechts P, Van Meerbeek B, Vanherle G. Polymerization shrinkage and elasticity of flowable composites and filled adhesives. Dent Mater 1999 Mar;15(2):128-137.

18. Meredith N, Setchell DJ. In vitro measurement of cuspal strain and displacement in composite restored teeth. J Dent 1997 May-Jul;25(3-4):331-337.

19. Peutzfeldt A, Asmussen E. Determinants of in vitro gap formation of resin composites. J Dent 2004 Feb;32(2):109-115.

20. Cenci M, Demarco F, de Carvalho R. Class II composite resin restorations with two polymerization techniques: relationship between microtensile bond strength and marginal leakage. J Dent 2005 Aug;33(7):603-610.

21. Furness A, Tadros MY, Looney SW, Rueggeberg FA. Effect of bulk/incremental fill on internal gap formation of bulk-fill composites. J Dent 2014;42(4):439-449.

22. Estafan D, Agosta C. Eliminating microleakage from the composite resin system. Gen Dent 2003;51(6):506-509.

23. Orłowski M, Tarczydło B, Chałas R. Evaluation of marginal integrity of four bulk-fill dental composite materials: in vitro study. Sci World J 2015;2015:701262.

24. Tantbirojn D, Versluis A, Pintado MR, DeLong R, Douglas WH. Tooth deformation patterns in molars after composite restoration. Dent Mater 2004 Jul;20(6):535-542.
25. McCullock AJ, Smith BG. In vitro studies of cuspal movement produced by adhesive restorative materials. Br Dent J 1986 Dec 6;161(11):405-409.

26. Blaser PK, Lund MR, Cochran MA, Potter RH. Effect of designs of class II preparations on resistance of teeth to fracture. Oper Dent 1983 Winter;8(1):6-10.

27. Alomari QD, Reinhardt JW, Boyer DB. Effect of liners on cusp deflection and gap formation in composite restorations. Oper Dent 2001;26(4):406-411.

28. Jantarat J, Panitvisai P, Palamara JE, Messer HH. Comparison of methods for measuring cuspal deformation in teeth. J Dent 2001 Jan;29(1):75-82.

29. González López S, Sanz Chinesta MV, Ceballos García L, de Haro Gasquet F, González Rodríguez MP. Influence of cavity type and size of composite restorations on cuspal flexure. Med Oral Patol Oral Cir Bucal 2006 Nov 1;11(6):E536-E540.

30. González-López S, Vilchez Díaz MA, de Haro-Gasquet F, Ceballos L, de Haro-Muñoz C. Cuspal flexure of teeth with composite restorations subjected to occlusal loading. J Adhes Dent 2007 Feb;9(1):11-15.

31. Behery H, El-Mowafy O, El-Badrawy W, Saleh B, Nabih S. Cuspal deflection of premolars restored with bulk-fill composite resins. J Esthet Restor Dent 2016 Mar-Apr;28(2): 122-130.

32. Garapati S, Das M, Mujeeb A, Dey S, Kiswe SP. Cuspal movement and microleakage in premolar teeth restored with posterior restorative materials. J Int Oral Health 2014 Sep;6(5): 47-50.

33. Karaman E, Ozgunaltay G. Cuspal deflection in premolar teeth restored using current composite resins with and without resin-modified glass ionomer liner. Oper Dent 2013 May-Jun;38(3):282-289.

34. Cara RR, Fleming GJ, Palin WM, Walmsley AD, Burke FJ. Cuspal deflection and microleakage in premolar teeth restored with resin-based composites with and without an intermediary flowable layer. J Dent 2007 Jun;35(6):482-489.

35. Beznos C. Microleakage at the cervical margin of composite class II cavities with different restorative techniques. Oper Dent 2001;26(1):60-69.

36. El-Damanhoury H, Platt J. Polymerization shrinkage stress kinetics and related properties of bulk-fill resin composites. Oper Dent 2014 Jul-Aug;39(4):374-382.

37. Kalra S, Singh A, Gupta M, Chadha V. Ormocer: an aesthetic direct restorative material; an in vitro study comparing the marginal sealing ability of organically modified ceramics and a hybrid composite using an ormocer-based bonding agent and a conventional fifth-generation bonding agent. Contemp Clin Dent 2012 Jan;3(1):48-53.

38. Elsayad I. Cuspal movement and gap formation in premolars restored with preheated resin composite. Oper Dent 2009 Nov-Dec;34(6):725-731.

39. Sakaguchi RL, Power JM. Craig's restorative dental materials, 13rd ed. Texas; 2012. $177 \mathrm{p}$.

40. Segura A, Donly KJ. In vitro posterior composite polymerization recovery following hygroscopic expansion. J Oral Rehabil 1993 Sep;20(5):495-499. 